\title{
Musculoskeletal injuries among adolescent cricketers in Zimbabwe
}

\begin{abstract}
Aim: This is a study to describe and document cricket-related musculoskeletal injuries among high school male cricketers in Zimbabwe during inter-provincial competitions.

Methods: This is a retrospective descriptive study. 240 male cricketers had been taken for this sample. An edited self-reported musculoskeletal questionnaire for pain assessment was used. The questionnaire was designed to obtain musculoskeletal pain, location of injury, type of injury and injury severity. The SPSS version 20.0 statistical software was used for data entry and statistical analysis. Pearson correlation analysis and Chi-square tests were performed. P-value $\leq 0.05$ was regarded as significant.

Results: Of the 240 adolescents' high school cricketers surveyed, $81.25 \%$ experienced cricket-related musculoskeletal pain and injury within the previous season. There was a $35 \%$ prevalence of injuries among cricket players. The knee, lower back and shoulder were the three common most susceptible anatomical sites of musculoskeletal pain and injuries. Bowlers (36\%) and batsmen (32\%) had sustained highest percentage of injuries and compared to all-rounders $(22 \%)$ and wicket-keepers (10\%).

Conclusion: Prevalence of musculoskeletal injury/pain is elevated among adolescents' school boy cricketers. Male cricketers residing in Kwekwe, Zimbabwe experienced a high prevalence of musculoskeletal, ankle, knee, lower back, and shoulder pain. Coaches' conditioning training programs and early rehabilitation by physiotherapists are indispensable to condense the injury rate in high school cricket.
\end{abstract}

Keywords: all-rounder, batsmen, bowlers, musculoskeletal injury, sprain, strain

\author{
Volume 2 Issue I - 2018
}

\section{Adiele Dube,' Morgan Patrick D Gundani, Satish Rastogi ${ }^{3}$ \\ 'Department of Emergency Medical Care, Emergency Medical Rescue Services, Zimbabwe \\ ${ }^{2}$ Senior Lecturer, Department of Sports Science \& Coaching, National University of Science and Technology, Zimbabwe ${ }^{3}$ Professor \& Coordinator, Institute of Distance Education, University of Swaziland, Swaziland}

Correspondence: Adiele Dube, Department of Emergency Medical Care, Emergency Medical Rescue Services, Zimbabwe, Email adieledube@yahoo.com

Received: February 12, 2018 | Published: February 23, 2018

\section{Introduction}

Many sports have been researched on, for example, soccer basketball and athletics among others due to their popularity in Zimbabwean schools. In African continent, there are few countries playing competitive cricket on One Day International (ODI) and T-test and these are South Africa, Kenya and Zimbabwe. Due that fact not much has been said in school cricket. The uniqueness of cricket is that unlike other target games like archery, darts and shooting; cricket demands hitting a target whilst in motion. This angular motion has a restrictive range of motion which can cause more complicated injuries to the player. Also cricket a more protected target is used despite the complexity of ROM and angular restrictions. Zimbabwe has become more popular in male and female professional cricket and street cricket in the recent decades. This sport is dynamic and involves a scientific knowledge to cope with the new developments in the game. It involves many abstract skills and movements which need to be enhanced so that players are guaranteed that their bodies are kept in shape and strong. ${ }^{1,2}$ At a young age, cricket is for enjoyment, health and professional development. Inevitably, injury is potential outcomes of participation hence young athletes are vulnerable to cartilage which is less resistance to repetitive micro injury, apophysis and growth plate's injuries. ${ }^{1,3-7}$ Competitive element intervenes young players' decreased flexibility due to pronounced growth spurt through training harder and longer times which lead to varied physiologic response to exercise hence injuries. ${ }^{4,-9}$
Bowling, batting and fielding are the three unique aspects of the game of cricket which are associated with risks of injury due to its repetitive nature and played often for long periods of time. ${ }^{1,10}$ In cricket, musculoskeletal pain and injuries are very common. They can occur when a player had rapid rotational movements, collisions with other players, struck by a ball or bat, sliding and diving during fielding and over-use injuries; thus physical macro trauma and microtrauma. ${ }^{1,9,11}$ A single high force and impact incident results in a macro-trauma which whilst micro-trauma is a result of repetitive or chronic injury which can have a lifetime. ${ }^{1,12}$ Importantly, inadequate nutritional intake, physical training and psychological preparation of players have great effects on muscle strength, endurance, flexibility, agility and fitness in the field of play and therefore hinder player performance in the game of cricket. ${ }^{7,13}$

Literature concentrate on cricket-related injuries affecting elite fastbowlers; spinal abnormalities in young fast-bowlers, musculoskeletal pain among adolescent cricketers and prevalence of cricket-related musculoskeletal injuries among elite cricketers mentioning that the most common anatomical sites of injury identified were lower limb, upper limb and lower back $\mathrm{k}^{1,2,9,11,14-18}$ whilst limited information exists regarding the Southern Africa high cricketer. It is imperative that the lack of information exists regarding the epidemiology of musculoskeletal pain and injury for high school cricketers. The current study aims at describing and documenting cricket-related musculoskeletal injuries among high school cricketers in Zimbabwe during inter-schools' competitions. 


\section{Materials and methods}

\section{Design}

The study was a retrospective descriptive study which documented male cricketers' musculoskeletal pain and injuries in a year's period. The incidence of injuries documented was during the National Association of School Heads (NASH) U19 cricket championships, which was held in 2015-16 season. Both qualitative and quantitative designs were used. For this purpose, all the teams participating in these competitions were invited to take part in this study.

\section{Sample size and sampling}

A total of 252 subjects who volunteered to participate were recruited. In Zimbabwe cricket has been franchised into four main regions; southern, central eastern and northern. This study focus on the central region under auspices of Midwest Rhinos franchise and the paper will not compare injuries sustained in different regions. Only top cricketing schools among the 12 high schools in the region were selected. These players were from five high schools namely; Goldridge, Kwekwe, Mbizo, Shungu, and Rutendo.

\section{Ethical considerations}

Ethics approval for this study was obtained from the National University of Science and Technology (NUST) Sports science and coaching department and permission to use the schools were obtained from the Ministry of Primary and Secondary Education, Midlands Province and School Heads. Informed consent was obtained from each of the study subjects and their parents or guardians. Only cricketers with both written assent and consent were used as subjects in this study. The researcher kept subjects' identity anonymous and confidential.

\section{Data collection}

An edited self-reported musculoskeletal questionnaire (combined pain assessment and Borg CR 10 scales) was used. The questionnaire was designed to obtain musculoskeletal pain, location of injury, type of injury and injury severity. At the beginning of the season cricket players were taught how to report pain and injuries. Team medics were used as research assistants to monitor the record of injury from individual players after a match. The information for each injury was obtained throughout the season. A summary of individual player's seasonal record of injuries was used to complete the questionnaire. Other medical records from other sports played were not obtained since they were not necessary.

\section{Data analysis}

The SPSS version 20.0 statistical software was used for data entry and statistical analysis. Pearson correlation analysis and Chi-square tests were performed. $P$-value $\leq 0.05$ was regarded as significant. Hypothesis test was done on the descriptive.

\section{Results}

The response rate (240/245) 98\%. 5 questionnaires were inappropriately completed hence making them invalid.

Anthropometric and demographic characteristics are shown in Table 1. Table 2 shows prevalence of player's musculoskeletal injury in relation to the players' role among cricketers. Out of 195 players investigated for pain; $36 \%$ were bowlers, $32 \%$ were batsmen, $22 \%$ of all-rounders, and least were wicket-keepers with $10 \%$. The anatomical site for specific musculoskeletal pain and injury levels on cricket player is shown in Figure 1. Distributions of cricket-related musculoskeletal pain in relation to anatomical sites were; knee (35\%), lower back $(30 \%)$, shoulder $(23 \%)$, thigh $(18 \%)$, hands and wrist $(16 \%)$ and $15 \%$ for the neck. Most common injured is the lower limb as compared to the upper limb. Figure 2 shows distribution and extent of each type of injury suffered by high school boys' cricketers. Most common injuries/pain suffered by cricketers was sprain and strain; however, sprain $(45 \%)$ was more than strain $(30 \%)$, wounds were $15 \%, 5 \%$ fractures, dislocation $3 \%$ and the least were cramps with 2\% (Figure 3).

Table 1 Anthropometric measurements of the study population $(\mathrm{n}=252)$

\begin{tabular}{lll}
\hline Variable & Mean \pm sd & P-value \\
\hline Age (years) & $16.4 \pm 2.4$ & $0.004^{* *}$ \\
Body mass $(\mathrm{kg})$ & $64.3 \pm 14.8$ & \\
Height $(\mathrm{cm})$ & $1.66 \pm 0.12$ & \\
BMI $\left(\mathrm{kg} / \mathrm{m}^{2}\right)$ & $20.7 \pm 2.2$ & \\
\hline
\end{tabular}

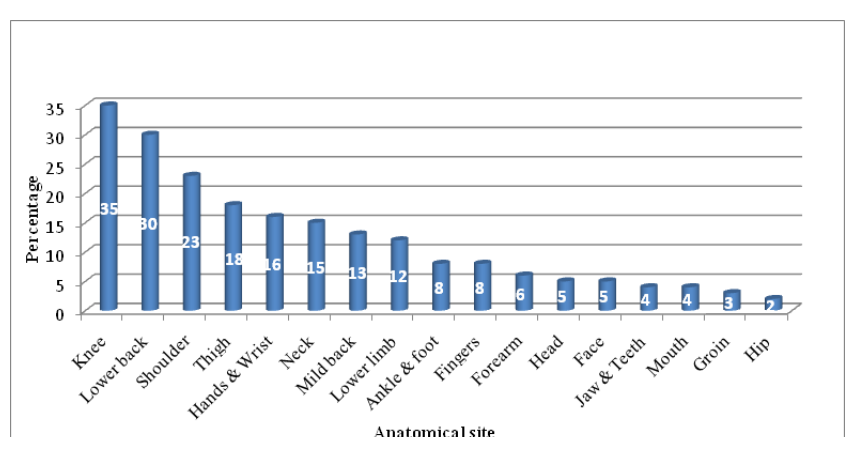

Figure 1 Prevalence of cricket-related musculoskeletal pain and injury at specific anatomical sites $(n=195), p<0.0001$.

Table 2 Prevalence of musculosketal pain and injury among cricketers $(\mathrm{n}=195)$

\begin{tabular}{|c|c|c|c|c|c|}
\hline \multirow{2}{*}{ Player's role } & \multicolumn{2}{|c|}{ NO } & \multicolumn{2}{|c|}{ YES } & \multirow[b]{2}{*}{ P-valu } \\
\hline & $\mathbf{n}$ & $\%$ & $\mathbf{n}$ & $\%$ & \\
\hline Bowlers & 18 & 25.7 & 52 & 74.3 & $0.001 * *$ \\
\hline Batsmen & 17 & 27.4 & 45 & 72.6 & $0.002 * *$ \\
\hline All-rounders & 21 & 48.8 & 22 & 51.2 & 0.861 \\
\hline Wicket-keepers & 5 & 25 & 15 & 75 & $0.034 * *$ \\
\hline
\end{tabular}

Two way proportional test.

$* * \mathrm{p}<0.05$ values considered significant 


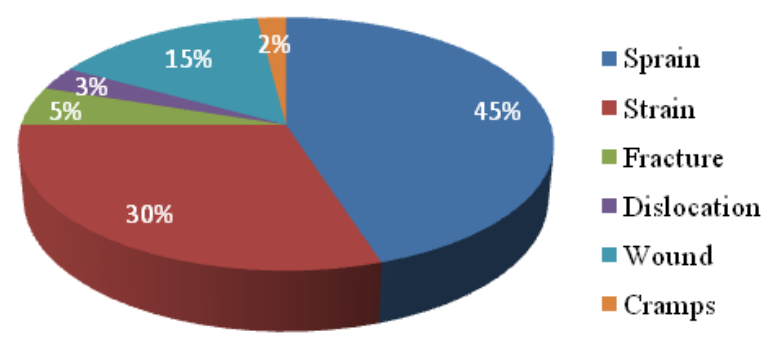

Figure 2 Types of injuries most recorded from cricketers.

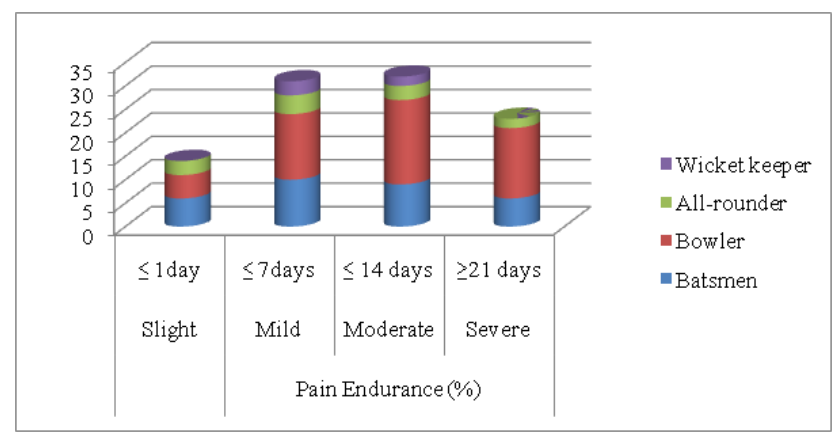

Figure 3 Severity of pain and injury, recovering period in days.

\section{Discussion}

The principal objective of this study was to investigate the prevalence and nature of cricket-related musculoskeletal pain among male adolescent cricketers in Kwekwe. In this study, the anatomical location of pain, intensity of pain and duration of pain (nature of pain) clearly indicates musculoskeletal pain pathologies, hence indicating the prevalence of cricket-related musculoskeletal pain. Among the 240 adolescents high school boy cricketers surveyed, 195 (81.25\%) experienced cricket-related musculoskeletal pain and injury within the previous season $(\mathrm{p}<0.001)$. There is a $35 \%$ of prevalence of injuries among cricket players. These findings are similar and match with other international injury surveys which recorded the prevalence of male adolescent cricket-related musculoskeletal pain and injury. ${ }^{1,12,19,20}$

The knee, lower back, and shoulder were the three common most vulnerable anatomical site of musculoskeletal pain and injuries in cricket players $(\mathrm{p}<0.001)$. Basing on role specificity; bowlers $(36 \%)$ and batsmen $(32 \%)$ had a high prevalence of injuries and were the most injured playing position as compared to all-rounders $(22 \%)$ and wicket-keepers $(10 \%)$. Biomechanically, the bowling action applies large amount of forces onto the spine, which adversely acts on it causing pain and injury. ${ }^{15}$ Also, high percentage of lower back pain and injuries was a result of repeated hyper-extension of trunk before releasing the ball while bowling and during batting -offside pulling the ball. Similar to other international studies, the findings supported other previous findings regarding to bowlers being at the greatest risk of musculoskeletal pain and injury and the lower limbs being the most commonly injured site. , $, 2,5,9,10,14-16,20-23$ Higher lower limb injuries were a result of; bare and uneven ground, improper shoes and technically from run up while bowling, fielding and making runs between wickets. ${ }^{19}$
Batsmen and wicket-keepers were subjects who mostly experienced knee pain. This is because batsmen display movements which are either on through forward propulsion or back foot backwards propulsion. These movements mount pressure and tension on the knee and surrounding joints of the patella during flexion and extension, placing the knee joint at increased risk of injury. ${ }^{24}$ This is supported by Noorbhai et al. ${ }^{1}$ wicket-keepers spent most of the time kneeling down and flexing their knees while playing, which also increases their risk of pain at the knee joint. The findings were in line with literature that the third most common site of injury is shoulder $(23 \%) .^{1,17}$ This resulted from repetitive inappropriate shoulder movements during bowling, poor throwing technique when fielding. When bowling, batting or fielding repeated throwing using the same arm may result in shoulder overuse, causing some degenerative changes in the rotator cuff, tendinitis and over-stretching or tear of the supraspinatus tendon can be witnessed. ${ }^{20}$

The two most common types of injuries among cricketers were sprain (45\%) and strain (30\%) compared among wounds, fractures, dislocation and cramps. Similar findings to the present study were found in line with those of Stretch ${ }^{9}$, Kumar et al. ${ }^{18}$, Das et al. ${ }^{11}$, Stretch \& Trella. ${ }^{22}$ Training high schools' cricketers need coaches, parents and clubs who are knowledgeable to strength and flexibility balanced training to produce better performance and fewer injuries/ pain. Noorbhai et al. ${ }^{1}$ emaphasised that the chances rate of injury and pain among players can he reduced by initiating more strength and flexibility training.

\section{Conclusion}

It was noted that prevalence of injuries in high school cricket is high in bowlers than other play positions. This, therefore means that coaches should consider conditioning of players, warm up activities should address nature of injuries and injured part noted, also fitness testing for endurance, agility, power, strength and flexibility need to be introduced in the training program to minimize the rate of injury. Database for cricket-related musculoskeletal injury of male adolescent cricketers in Zimbabwe is essential for coaches, physicians and physiotherapists to condense the injury rate. Future researchers may consider the following; analysis of player position and injury, improvement of play technique, playtime visa-vie injury prevention and consideration of a specific number of over for specific age groups to reduce overuse and injuries.

\section{Limitations of the study}

Cricket playtime and time of research was retrospective. Despite having taught how to report pain and injury, the cricketers may have not reported more than one injury. Data collection was done late after season and was only from the central region out of the four regions.

\section{Acknowledgements}

None.

\section{Conflict of interest}

The author declares no competing conflict interests.

\section{References}

1. Noorbhai MH, Essack FM, Thwala SN, et al. Prevalence of among adolescent cricketers in Kwa-Zulu Natal. South African Journal of Sports Medicine. 2012;24(1):3-9. 
2. Aginsky KD, Lategan L, Stretch RA. Shoulder injuries in provincial male fast bowlers-predisposing factors. S Afr J Sports Med. 2004;16(1):25-28.

3. Watters DA, Brooks S, Elton RA, et al. Sports injuries in an accident and emergency department. Arch Emerg Med. 1984;1(2):105-111.

4. Williams JM, Wright P, Currie CE, et al. Sports related injuries in Scottish adolescents aged 11-15. Br J Sports Med. 1998;32(4): 291-296.

5. Sreekaarini I, Eapen C, Zulfeequer CP. Prevalence of Sports Injuries in Adolescent Athletes. J Athl Enhancement. 2014;3(5).

6. Shanmugam C, Maffulli N. Sports injuries in children. Br Med Bull. 2008;86(1):33-57.

7. Petersen CJ, Pyne DB, Dawson BT, et al. Comparison training and game demands of national level cricketers. J Strength Cond Res. 2011;25(5):1306-1311.

8. Emery C, Tyreman H. Sport participation, sport injury, risk factors and sport safety practices in Calgary and area junior high schools. Paediatr Child Health. 2009;14(7):439-444

9. Stretch RA. Cricket injuries: a longitudinal study of the nature of injuries to South African cricketers. Br J Sports Med. 2003;37(3):250-253.

10. Myers P, Brien OS. Cricket: Injuries, Rehabilitation and Training. London: Lippincott Williams \& Wilkins; 2001:124-136.

11. Das NS, Usman J, Choudhury D, et al. Nature and Pattern of Cricket Injuries: The Asian Cricket Council Under-19, Elite Cup, 2013. PLoS One. 2014;9(6):e100028.

12. Davies R, Randt DR, Venter D. Cricket nature and incidence of fast bowlers' injuries of elite junior level and associated risk factors. South African Journal of Physical Health Education and Recreation. 2008; 20(4):115-118

13. Milsom NM, Barnard JG, Stretch RA. Seasonal incidence and nature of cricket injuries among elite South African schoolboy cricketers. S Afr J Sports Med. 2007;19(3):80-84.
14. Dennis RJ, Finch CF, Farhart PJ. Is bowling workload a risk factor for injury to Australian junior cricket fast bowlers? $\mathrm{Br} J$ Sports Med. 2005;39(11):843-846.

15. Giles K, Musa I. A survey of glenohumeral joint rotational range and non-specific shoulder pain in elite cricketers. PhysTher Sport. 2008;9(3):109-116

16. Hardcastle P, Annear P, Foster DH, et al. Spinal abnormalities in young fast bowlers. J Bone Joint Surg Br. 1992;74(3):421-425.

17. Frost WL, Chalmers DJ. Injury in elite New Zealand cricketers 2002-2008: descriptive epidemiology. Br J Sports Med. 2014;48(12):1002-1007.

18. Kumar S, Kulandaivelan S, Kaur J, et al. One year prevalence of musculoskeletal disorder among cricket Players in Haryana: A retrospective study. International Journal of Physical Education, Sports and Health. 2015;2(2):75-77.

19. Ellapen TJ, Demartinis R, Hughes T, et al. The incidence of hockey ankle injuries in KwaZulu-Natal. AJPHERD. 2009;15(3):417-423.

20. Orchard JW, Newman D, Stretch R, et al. Methods for injury surveillance in international cricket. J Sci Med Sport. 2005;8(1):1-14

21. Stretch R A, Lambert M. Junior cricketers are not a smaller version of adult cricketers: A 5-year investigation of injuries in elite junior cricketers. $S$ Afr J SM. 2014;26(4):123-127.

22. Stretch RA, Trella C. A 3-year investigation into the incidence and nature of cricket injuries in elite South African schoolboy cricketers. S Afr J Sports Med. 2012;24(1):10-14.

23. Prince WE. Rehabilitation Techniques for Sports Medicine and Athletic Training. $5^{\text {th }}$ ed. New York: The McGraw Hill Company; 2011:47-92.

24. Woolmer B, Noakes TD, Moffett H. Bob Woolmer's Art and Science of Cricket. Cape Town: Struik Publishers; 2009:86-322, 464-520,526-630. 